\title{
Zentralvorstandssitzung vom 19. Januar 2012
}

Ärztliche Einkommensverhältnisse - Die FMH erhebt 2012 ausschliesslich das Einkommen der ambulant tätigen Ärzteschaft. Das Einkommen der Spitalärzte - erstmals 2011 ermittelt - soll wie vorgesehen alle zwei Jahre erfasst werden.

Grossveranstaltungen - Bestimmungen und Kontrollen zur Erstellung eines Sanitätskonzeptes bei Grossveranstaltungen sind häufig minimal oder fehlen gänzlich. Die Plattform Rettungswesen der FMH hat die Gesundheitsdirektorenkonferenz und die Justizdirektorenkonferenz mit einem Schreiben auf diese Mängel aufmerksam gemacht.

TARVISION, Grundversorger-Kapitel - Im Rahmen der Tarifrevision TARVISION gilt es, die Grundversorgung im entsprechenden Kapitel der TARMEDTarifstruktur möglichst korrekt abzubilden. Zugangsberechtigt für das Grundversorger-Kapitel sind Ärztinnen und Ärzte mit den Facharzttiteln Allgemeine Innere Medizin AIM, Kinder- und Jugend- medizin sowie die Doppeltitelträger, letztere mit gewissen Bedingungen.

Absichtserklärung mit $\mathbf{H}_{+}-\mathrm{Im}$ Zusammenhang mit TARVISION, der laufenden Tarifrevision TARMED, haben die FMH und $\mathrm{H}+$ eine gemeinsame Absichtserklärung unterzeichnet, welche die Zusammenarbeit regelt. Gemeinsam wollen die beiden Organisationen sowohl den ambulanten als auch den stationären Bereich des TARMED revidieren.

Sportförderungsverordnungen - Die FMH äussert sich im Rahmen der Vernehmlassung zu den Sportförderungsverordnungen. Diese sehen eine Steigerung der Sport- und Bewegungsaktivitäten auf allen Altersstufen vor. Die Verbindung der Schweizer Ärztinnen und Ärzte befürwortet die Anliegen der Verordnungen und regt einige Modifikationen an. Eingehendere Information zu den FMH-Stellungnahmen findet man über www.fmh.ch $\rightarrow$ POLITIK \& MEDIEN $\rightarrow$ Vernehmlassungen.

\section{Durchblick bei Rechtsfragen.} Der Leitfaden für juristisches Basiswissen.

«Rechtliche Grundlagen im medizinischen Alltag». Für Mitglieder kostenlos.

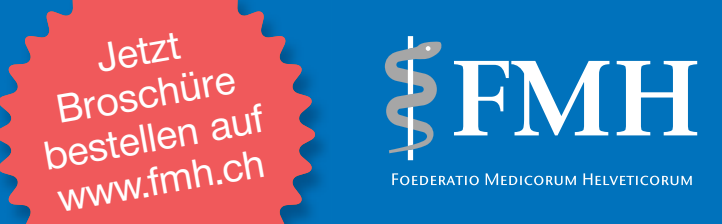

